\title{
GÉNERO, DEREGHO Y GULTURA EN LOS LUGARES DE TRABAJO JURÍDICOS: UN CASO CHILENO DE ESTUDIO
}

\author{
Ann C. MaGinley*
}

\begin{abstract}
Resumen
La autora entrevistó abogados y abogadas chilenas con el objeto de analizar los efectos jurídicos y culturales de sus condiciones laborales. El estudio determinó que la realidad de las responsabilidades familiares de las mujeres y los estereotipos sobre sus debilidades para trabajar como líderes perjudica sus carreras como abogadas. A pesar de que la ley permite a las madres compartir su post-natal de seis meses con los padres, ellos rara vez lo toman debido a la reprobación de la sociedad y sus empleadores, práctica que refuerza la separación tradicional entre los roles del hombre y la mujer. El artículo concluye que la cultura tiene un impacto aún mayor que el derecho sobre las condiciones de género del trabajo de los abogados, pero que el derecho también puede afectar el comportamiento. La cultura no es estática, y los legisladores debieran considerar los efectos de las leyes y las consecuencias no deseadas al proponer nueva legislación que corrija las desigualdades.
\end{abstract}

Palabras claves: Abogadas, discriminación de género, género, estereotipos, post-natal, derecho $y$ cultura.

\section{INTRODUGGIÓN: DEREGHO VS. GULTURA EN LOS GÍRCULOS JURÍDICOS GHILENOS}

A pesar de que Chile es un país tradicional, está cambiando rápidamente. ${ }^{1} \mathrm{Ha}$ elegido dos veces a una mujer socialista como presidenta, Michelle Bachelet, quien ha realizado cambios significativos en el derecho y en derechos de la mujer. ${ }^{2}$ Chile

\footnotetext{
University of Nevada, Las Vegas, Boyd School of Law, Estados Unidos (ann.mcginley@unlv. edu). Este artículo es una versión abreviada de un artículo más detallado que aparecerá en Arizona Law Review, McGinley (2018). Mis agradecimientos a los editores de la Arizona Law Review por darme su autorización para reproducir algunos pasajes aquí. Agradezco a Sergio Gamonal por su apoyo intelectual y personal, a Alberto Pino por su ayuda en la edición de este artículo, y a todos los entrevistados anónimos que hicieron posible este proyecto. Artículo recibido el 21 de mayo de 2018, y aceptado para su publicación el 26 de junio de 2018. Traducción de Alberto Pino Emhart.

1 El divorcio era ilegal en Chile hasta el 2004, pero muchas personas casadas vivían con otras personas y tenían hijos fuera del ámbito matrimonial. Hepburn y Simon (2006), pp. 50-1. Las clases más acomodadas encontraron una forma de solucionar el problema. Agradezco a Sergio Gamonal por esta perspectiva. El aborto fue legalizado solo en 2017 por tres causales solamente. DidEs y Maulhardt (2015). El Nuevo Presidente, Sebastián Piñera, se presentó como un conservador, y podría desmantelar las iniciativas de Bachelet. El Mostrador (2017); Bonnefoy y LondoÑo (2017).

2 MaGinley (2018).
} 
tiene una ley relativamente nueva que protege los derechos fundamentales de los trabajadores privados y funcionarios públicos. ${ }^{3}$ En Chile también se establece un generoso sistema de permisos de pre y post-natal remunerados, y se prohíbe despedir a mujeres y madres que se encuentren con fuero maternal, salvo causales graves. ${ }^{4} \mathrm{Se}$ requiere una empresa de veinte o más trabajadoras mujeres para obtener subsidios para el cuidado de los niños, ${ }^{5}$ y se les concede a las madres tiempos libres para alimentar a sus hijos. ${ }^{6}$ Dadas estas y otras leyes protectoras de la familia que por lejos exceden la protección en Estados Unidos, si el derecho regula el comportamiento de los empleadores, las trabajadoras mujeres en Chile debieran prosperar, a menos que una cultura de discriminación sea dominante o las leyes tengan una consecuencia no deseada.

Dado el contraste aparente entre su progresiva legislación laboral que apoya las mujeres en los lugares de trabajo y la cultura tradicional que concibe a las mujeres como las responsables de la familia, Chile presenta un ambiente excelente para responder la pregunta de si las leyes protectoras de la familia crean ambientes de trabajo igualitarios para mujeres, o si la cultura tradicional le priva de igualdad a las mujeres en sus lugares de trabajo. Para responder parcialmente esta pregunta, realicé un "estudio de bola de nieve" [snowball study $]^{7}$ entre enero y agosto de 2017 , que consiste

3 En 2006, Chile reformó el derecho laboral, de los artículos 485 a 495, que hacen aplicables la protección constitucional de derechos fundamentales a contratos laborales. Esta reforma creó un procedimiento especial para reivindicar los derechos fundamentales -la tutela laboral- que es aplicable a los empleadores públicos y privados. Ugarte Cataldo (2009), pp. 23-26.

Mientras que la llamada "Ley Zamudio" de 2012 prohíbe la discriminación basada en raza, color, sexo, identidad de género, orientación sexual, discapacidades, edad, afiliación política, y otras categorías, se establecen pocos remedios. Ley $\mathrm{N}^{\circ}$ 20.609, Art. 2. https://www.cbsnews.com/news/4-guiltyin-chile-gay-murder-that-led-to-hate-law/; https://www.leychile.cl/Navegar?idNorma=1042092

4 Las mujeres tienen seis semanas de permiso pre-natal financiado, y seis meses de post-natal financiado. Art. 195; Art. 197 bis. Si bien muchas abogadas se toman los seis meses completos, algunas me dijeron que se toman períodos más cortos. Véase Entrevistas CH03, p. 12; CH52, p. 14. Sin embargo, permitir a un trabajador volver antes a trabajar es ilegal en Chile. Los derechos laborales son irrenunciables. Las madres pueden compartir los tres meses finales de permiso postnatal con el padre del bebé, pero esto ocurre rara vez. Los hombres de manera independiente tienen cinco días de permiso pagado que algunos se toman, pero a pesar de los derechos otorgados por la ley, incluso tomarse cinco días es mal visto en muchas oficinas. Art. 195 inc. $2^{\circ}$ del Código del Trabajo. El Estado financia los permisos pre y post-natal, pero debido a la existencia de un tope, un abogado cuya remuneración excede del tope recibirá menos remuneraciones, o el empleador podría pagar la diferencia entre el tope y la remuneración de esa persona. La protección del fuero en contra de despedir a una mujer embarazada se encuentra en el art. 201. Entrevista CH10, p. 5. La protección chilena a las embarazadas y los permisos parentales son por lejos superiores a aquellas contempladas por el derecho estadounidense. MaGinLEY (2015).

5 Art. 203; Gamonal (2013), p. 65.

6 Art. 206. Allí se establece el "derecho de alimentación". La madre puede tomarse tiempo libre durante la jornada laboral o llegar una hora más tarde al trabajo, o irse una hora antes, o dividir el tiempo media hora en la mañana y media hora en la tarde. GAMONAL (2013), pp. 64-65.

7 Un estudio de "bola de nieve" se va desarrollando mientras progresa. El entrevistador le pide al entrevistado que recomiende a otros que voluntariamente participarían en el estudio. Un estudio de este tipo era apropiado porque se buscaban respuestas cualitativas más que cuantitativas, y ganarse 
en realizar extensas entrevistas a cincuenta y seis abogados chilenos y dos estudiantes de derecho, ${ }^{8}$ y tres foros de discusión con catorce estudiantes de derecho chilenos adicionales. ${ }^{9}$ Elegí los abogados como objetos de estudio porque son profesionales que, debido a su entrenamiento jurídico, se encuentran en una mejor posición que otros trabajadores para evitar la discriminación ilegal. Si los abogados experimentan o causan discriminación, es probable que la mayoría de los otros profesionales también lo sean. Más aún, porque soy abogada y profesora de derecho, entiendo la cultura jurídica y tengo acceso a los abogados como sujetos de estudio que no tendría con algún otro grupo. Debido a que mis entrevistas se limitaron a abogados, mis conclusiones solo son aplicables a abogados; puede que otros trabajadores profesionales y no-profesionales tengan experiencias distintas. Espero que otros puedan realizar investigación empírica y etnográfica sobre otros grupos de trabajadores para probar si mis conclusiones son transferibles.

la confianza de los sujetos entrevistados era crucial para el éxito del estudio. Aunque no se trata de un área altamente sensible, era suficientemente sensible como para que se requiriera que los entrevistados confiaran en el entrevistador. Como única entrevistadora, aunque extranjera, dado que era una abogada y profesora de derecho en Estados Unidos, y que fui capaz de relacionarme con los entrevistados, me gané su confianza, y ellos contactaron otros abogados y jueces que conocían para preguntarles si les gustaría participar. El primer grupo de estudiantes y graduados de magíster fue elegido por conveniencia (una "muestra de conveniencia"), pero mientras crecía el estudio, fui ampliándolo considerando abogados de todas las distintas especialidades en distintos lugares de trabajo, de distintas edades y géneros, así como también jueces. También le pedí a profesores universitarios que refirieran a abogados para entrevistarlos para el proyecto. Esto condujo a nuevas cadenas que alcanzaron ampliamente a la comunidad jurídica (una "muestra de juicio"). Finalmente, agregué grupos de discusión de estudiantes para considerar diferencias generacionales. Surgió una teoría de que una mirada a las diferencias generacionales podría llevar a soluciones innovadoras para problemas identificados por los entrevistados. Este último grupo fue una "muestra teórica". Los estudios de "bola de nieve" son aceptados por los investigadores de las ciencias sociales. Marshall (1996) pp. 523-4; Biernacki y WaLdorf (1981) pp. 143-8. A pesar de que el muestreo basado en bolas de nieve tiene algunas limitaciones - como la posibilidad de ausencia de grupos heterogéneos, y la reticencia de los sujetos a referir a otros para ser entrevistados-, no encontré ninguno de estos problemas. Primero, en cuanto a la heterogeneidad, dentro del grupo de sujetos, fui capaz de conversar con abogados y jueces de distintas edades, tipos de prácticas, género, educación, estatus en sus oficinas, etc. Segundo, no me enfrenté a los problemas que otros han tenido en las muestras de bola de nieve cuando el asunto objeto del estudio es demasiado sensible y/o los individuos encuestados no fueron parte de un grupo social más amplio. WATERs (2015) pp. 373-77.

8 "Abogado" en términos simples significa un graduado de una licenciatura de derecho que trabaja como abogado de litigación, como consultor, fiscal, asesor general, como juez, profesores de derecho que han practicado el derecho, y "relatores", similares a los law clerks en Estados Unidos pero que, además de los títulos en derecho, se han graduado de la Academia Judicial.

9 Este estudio fue iniciado con la ayuda de profesores de la Universidad Adolfo Ibáñez ("UAI"), particularmente de Sergio Gamonal C., Profesor Titular de Derecho y Director del programa de Magíster en Derecho Laboral y Seguridad Social. 


\section{METODOLOGÍA ${ }^{10}$}

\subsection{Las entrevistas}

Entre enero y agosto de 2017, entrevisté a abogados y abogadas, ${ }^{11}$ jueces, fiscales, profesores de derecho, y estudiantes de derecho, ${ }^{12}$ y realicé grupos de discusión de estudiantes de derecho. En total, fueron 72 sujetos de estudio. Debido a que la gran mayoría de estos entrevistados han trabajado en más de un cargo relacionado con el derecho, la muestra incluye abogados que han trabajado en más de 200 oficinas de abogados. Todas las entrevistas y grupos de discusión fueron realizados y transcritos en español. ${ }^{13}$ Todos los entrevistados y los participantes de los grupos de discusión firmaron formularios de consentimiento. A todos se les aseguró confidencialidad de sus identidades y se les asignaron números identificadores; sus nombres no fueron utilizados en las entrevistas y no aparecen en las grabaciones ni en las transcripciones. ${ }^{14}$ Algunos individuos fueron entrevistados en sus lugares de trabajo, mientras que otros lo fueron en lugares neutrales más cómodos, como cafés o salas de clases de universidades. Todas las entrevistas duraron entre una hora a 90 minutos. Los grupos de discusión tuvieron lugar en la Universidad Adolfo Ibáñez, en los cuales cada grupo promedió los cinco estudiantes. Los grupos también duraron entre una hora a 90 minutos. Las entrevistas se realizaron entre enero hasta principios de abril de 2017. Regresé para realizar los grupos de discusión en agosto de 2017.

10 El proyecto fue calificado como "exento" por la UNLV Social/Behavioral IRB, Las Vegas, Nevada en diciembre de 2016.

11 Era importante entrevistar tanto a abogados como mujeres, dado que este proyecto aborda el efecto que tiene el género - conceptos masculinos y femeninos de cómo una persona de un género de nacimiento particular debiera comportarse- sobre los abogados. Era crucial: 1) considerar los puntos de vista de abogados y abogadas, para ver si tenían diferentes percepciones de género, y sus efectos tanto en hombres como mujeres; 2) revisar las leyes laborales vigentes en Chile, y cómo ellas operan en la práctica afectando tanto a abogados como abogadas; y 3) considerar si la cultura influye en cómo operan las leyes en la práctica. Si bien muchos piensan que el género se relaciona solo con las mujeres, los hombres también tienen género, y los estereotipos de la sociedad acerca de los roles de género apropiados afectan cómo los hombres y mujeres actúan. McGinLEY (2016) pp. 15-16. A mi juicio, los conceptos de masculinidad afectan en cómo se comportan los hombres, y a veces los priva de tener relaciones positivas con sus hijos. Un buen ejemplo de la importancia de atender al género en relación tanto a los hombres como a las mujeres, es que el derecho chileno permite a una madre darle a los padres de los hijos los últimos tres meses de su permiso post-natal. Interesantemente, la gran mayoría de los sujetos -hombres y mujeres-, señalaron que los hombres no se toman el post-natal porque ello es "mal visto" por sus empleadores y colegas.

12 "Fiscal" tiene distintos significados en Chile. El "fiscal" es un persecutor penal, pero la palabra también significa asesor legal general de una empresa. Utilizo la palabra en ambos sentidos. Entrevisté tanto a persecutores penales como asesores. Los chilenos normalmente distinguen entre abogados y fiscales, pero en Estados Unidos no hacemos esa distinción.

13 Las traducciones entre comillas en este artículo son mías.

14 Dada la sensibilidad de la materia y las amplias premisas que planteo de no identificar a las personas entrevistadas, no puedo nombrar los estudios jurídicos, pero había una gran diversidad de tipos de estudios donde trabajaban los entrevistados. 


\subsection{Perfiles de los entrevistados y su experiencia}

Entrevisté a 56 abogados chilenos, y dos estudiantes de derecho, ${ }^{15}$ y realicé tres grupos de discusión de 14 estudiantes de derecho chileno adicionales. Los sujetos entrevistados fueron $38 \%$ hombres y $62 \%$ mujeres, y su rango de edad era entre 25 a 55 años, con una mediana de 38. Trabajaban en variados lugares relacionados con el derecho: juzgados de primera instancia de familia, civiles, penales y laborales; la Corte de Apelaciones de Santiago y la Corte Suprema de Chile; pequeños y grandes estudios jurídicos; grandes empresas internacionales multi-profesionales; organizaciones de servicio público incluyendo aquellas especializadas en representar víctimas y/o investigar las demandas de discriminación laboral, así como el Ministerio de la Mujer y la Equidad de Género; sociedades con fines de lucro; organizaciones no-gubernamentales sin fines de lucro; varias universidades; y la legislatura chilena. Los entrevistados litigan en el ámbito civil, penal, energético, de propiedad intelectual, internacional, laboral, legislativo e inmobiliario, en estudios jurídicos privados, oficinas estatales, y organizaciones no-gubernamentales. Los profesores universitarios enseñan derecho de la libre competencia, comercial, constitucional, penal, de familia, seguros, laboral, y clínicas jurídicas en las universidades. Muchos de los profesores universitarios han litigado, y algunos de los abogados litigantes y jueces también son profesores de derecho por hora.

Todos los entrevistados tienen licenciatura en derecho. Muchos tienen también diplomado ${ }^{16}$ o magíster. ${ }^{17}$ Unos pocos tienen doctorados. Los entrevistados se graduaron de varias universidades en Chile y en el exterior. Algunos hablan inglés y otros idiomas además de su español nativo.

Los estudiantes de los grupos de discusión son estudiantes de derecho de tercer y quinto año, entre el rango de 20 a 24 años de edad. También se realizaron entrevistas extendidas a dos estudiantes que estudian en una facultad de derecho en Viña del Mar. Estos estudiantes tienen 21 y 30 años de edad respectivamente, y están en el cuarto año de su educación jurídica. Doce de los dieciséis estudiantes de pregrado eran mujeres; cuatro eran hombres.

15 Utilizo la palabra "abogado" en sentido amplio, para referirme a la persona que se graduó de una universidad con un grado académico de derecho, y que está usando dicho grado académico para trabajar como abogado en litigación, consultoría, o como persecutor, como asesor general en un negocio, o como juez. También incluí profesores de derecho que previamente han practicado derecho o que continúan haciéndolo, y "relatores", similares a los law clerks en Estados Unidos pero que, además de los títulos en derecho, se han graduado de la Academia Judicial, y han trabajado como jueces en tribunales de primera instancia. A algunos jueces de primera instancia se les pide que "relaten" en alguna de las Cortes de Apelaciones o en la Corte Suprema de Chile.

16 Un “diplomado" es un certificado de postgrado en un área específica del derecho.

17 "Magíster" es el término utilizado por los chilenos para referirse a un magíster equivalente a un grado de LL.M. en Estados Unidos. Para obtener un "magíster", los estudiantes deben realizar cursos en un área específica del derecho, son evaluados, y deben escribir una tesis original sobre un área de su elección. Un grado de "magíster" se realiza con frecuencia para que el abogado pueda realizar trabajo más especializado y ser más atractivo para los empleadores. Véase, por ejemplo, Entrevista CH26, p. 15. 


\subsection{Encontrando los sujetos}

Este estudio se inició con la ayuda de profesores de la Universidad Adolfo Ibáñez ("UAI") en Santiago, particularmente del profesor Sergio Gamonal C., Profesor Titular de Derecho ${ }^{18}$ y Director del Magíster en Derecho Laboral y Seguridad Social. ${ }^{19} \mathrm{Mi}$ afiliación como "Profesora Extranjera" en el programa de Magíster de la UAI a partir de 2012 me permitió tener acceso a los primeros entrevistados y los estudiantes que participaron en los grupos de discusión. Sin embargo, los entrevistados no se limitaron a aquellos que estudiaron en la UAI o que conocía el profesor Gamonal, sino que se realizó un estudio de bola de nieve que alcanzó una amplia variedad de sujetos en Santiago y unos pocos en Valparaíso. ${ }^{20}$

El proyecto comenzó con ocho entrevistados voluntarios: la mayoría de ellos eran estudiantes del programa de Magíster de la UAI Derecho Laboral y Seguridad Social, todos los cuales son abogados practicantes o jueces; unos pocos eran antiguos estudiantes o familiares de estudiantes que son abogados practicantes o jueces. A partir de ahí un estudio de bola de nieve comenzó. Al final de cada entrevista, se les pidió a los sujetos que recomendaran otros potenciales entrevistados. Controlé las áreas de práctica, género, edad, y experiencia de los sujetos potenciales para asegurarme de que un grupo representativo fuese entrevistado. Cuando el estudio necesitaba más entrevistas de socios de estudios, algunos profesores de la UAI y otras universidades me ayudaron a encontrar sujetos, y así comenzó otra cadena o bola de nieve. Cuando se necesitaban sujetos adicionales de una situación demográfica particular, le pedí a los entrevistados que recomendaran voluntarios dentro de dicha demografia, y así fue. Las entrevistas a abogados/jueces/profesores de derecho conformaron un grupo amplio. Los entrevistados no pertenecían a los mismos círculos sociales o laborales, y la mayoría no se conocía entre sí. Comencé a escuchar los mismos puntos de vista una y otra vez, lo que me ayudó a concluir que había agotado las respuestas sobre la materia.

El método de la bola de nieve tiene la ventaja de abarcar un amplio rango de individuos: abogados y abogadas de todas las edades que se graduaron de varias universidades, con diferentes especialidades, tipos de trabajos y prácticas del derecho. Para las entrevistas de estudiantes, tuve acceso a dos estudiantes que estudiaron en la Universidad Adolfo Ibáñez en Viña del Mar, uno a través del profesor Gamonal y otro que fue recomendado por el primer estudiante. Pero quedó claro después de

18 Un "Profesor Titular" es similar a un "Professor of Law" de Estados Unidos. El título se reserva para la persona que no solo tiene permanencia en el cargo, sino que también una destacada trayectoria en investigación.

19 Véase http://www.uai.cl/postgrados-y-diplomas/magister-en-derecho-laboral-y-seguridad-social.

20 Decidí limitar el estudio a Santiago porque es una ciudad de más de 6 millones de personas, donde vive más de un tercio de la población chilena, y sirve como centro del derecho, la política, el gobierno y los negocios en Chile. Aún más, todos los estudios calificados como "Big Law" en Chile se encuentran en Santiago. Véase De la MAZa et al. (2018), pp. 92-93. Entrevisté dos estudiantes y un juez de Valparaíso, porque estos sujetos fueron recomendados por otros como buenos entrevistados. Ambos estudiantes pronto estarán viviendo en Santiago y el juez originalmente es de Santiago. 
entrevistar a estos estudiantes y algunos de los abogados practicantes, que conversar con más estudiantes acerca del género y sus aspiraciones vocacionales sería útil. Varios de los entrevistados expresaron posturas distintas acerca de la pregunta sobre si las estudiantes mujeres eran ambiciosas respecto de sus carreras, y algunas abogadas jóvenes expresaron dudas acerca del mismo asunto. ${ }^{21}$ Algunos de los abogados mayores creían que los más jóvenes y los estudiantes de derecho no son tan ambiciosos como solían serlo. Más que tomar la caracterización que hacían los abogados mayores de los más jóvenes, les pregunté a estos últimos que practicaban derecho su opinión sobre este concepto, e hice grupos de discusión de estudiantes de derecho para probar cómo se percibían a ellos mismos. Los profesores de la UAI promocionaron y recolectaron nombres de estudiantes voluntarios que participaron en los grupos de discusión. Dado que la UAI es una universidad privada con un cuerpo estudiantil de clase media a alta, puede que los grupos de discusión no sean representativos de todos los estudiantes de derecho en Chile. Si bien intenté realizar grupos de discusión en la Universidad Diego Portales (UDP), ello no me fue posible. A pesar de que al menos un entrevistado - un profesor de la UDP- opinó que los estudiantes de la UAI serían más ricos y posiblemente las mujeres serían menos ambiciosas, los estudiantes de la UAI que participaron en los grupos de discusión no mostraron diferencias entre las respuestas de los hombres y las mujeres. Todos eran ambiciosos respecto de sus carreras, pero quizás de una manera distinta que las generaciones previas.

\subsection{Preguntas realizadas}

Las entrevistas siguieron un formato semi-estructurado. Las preguntas fueron creadas por adelantado, y a todos los entrevistados se les plantearon estas preguntas, comenzando por la historia laboral y educacional, la composición de género en sus lugares de trabajo, políticas vigentes en estos lugares de trabajo relacionados con género, su composición familiar, quién principalmente se hace cargo de las labores domésticas, los trabajos que tienen sus cónyuges, si se han tomado permisos pre o post-natales, si han trabajado media jornada, si las mujeres comparten su post-natal con los hombres, y si ello es así, si los hombres se toman el permiso, cómo el empleador reaccionaría o ha reaccionado, etc. Pregunté directamente si había alguna discriminación de género de cualquier tipo: contrataciones, remuneraciones, ascensos, acoso, o algún otro tratamiento diferenciado. Para el caso de los abogados más jóvenes que eran soleteros o que no tenían conexiones familiares, les pregunté cómo esperaban que fueran sus vidas más adelante, y qué asignación de trabajo en casa y trabajo en la oficina ocurriría para una pareja si pretendieran ser parte de una pareja. Para todos los entrevistados, continué las preguntas sobre sus preguntas y en último término, fueron seguidas de amplias preguntas abiertas acerca de las experiencias de los individuos en sus casas y lugares de trabajo de sus conocidos. Ejemplos de estas preguntas incluyen por qué piensan que sus empleadores tienen un gran porcentaje de abogados en posiciones bajas, pero tan pocas en posiciones de socias, etc. Una pregunta al final de una larga entrevista que motivó respuestas interesantes, fue

21 Entrevistas CH28, pp. 8-11; CH33, p. 16, CH17 pp. 3-4. 
preguntar a los padres si recomendarían a sus hijos practicar derecho, y si así era, en qué contexto. Al final de las entrevistas, le pedí a los entrevistados que hablaran con otros abogados que conocieran para preguntarles si querrían hablar conmigo. También realicé una pregunta abierta sobre si los entrevistados quisieran agregar algo a la conversación. Esta pregunta frecuentemente condujo a resultados interesantes.

Fui moderadora de los grupos de discusión, que comencé con una explicación de que había hablado con una serie de abogados tanto en Chile como en España, ${ }^{22}$ y que muchos abogados de mediana edad e incluso algunos jóvenes mencionaron que los estudiantes de derecho y los nuevos abogados no tienen las mismas ambiciones que sus contrapartes de edad más avanzada. ${ }^{23}$ Les pedí a los miembros del grupo que respondieran a esta afirmación. Mientras algunos respondían, otros estudiantes irrumpían y explicaban sus posturas, y les pregunté a todos ellos cuáles eran sus planes -familiares y vocacionales- para el futuro. Muchas de las preguntas repetían las de las entrevistas, pero eran preguntas relativas al futuro. ${ }^{24}$ Cada miembro de los tres grupos de discusión participó de igual medida en la discusión.

\subsection{Modo de análisis}

Cada grabación fue transcrita en español por hablantes nativos de español de Chile. Cuando las transcripciones terminaron, las leí numerosas veces, categoricé y codifiqué diferentes conceptos que surgían con frecuencia, y anoté cada transcripción. Una vez que completé esta tarea, volví a leer las transcripciones y las anotaciones, y comencé a redactar mis hallazgos y análisis. Este fue un proceso que demandó mucho tiempo, pero que me dirigió a un entendimiento comprehensivo de la información contenida en las transcripciones.

\section{ESTEREOTIPOS, RESPONSABILIDADES FAMILIARES, GULTURA Y DESIGUALDADES ESTRUCTURALES}

\subsection{Estudios jurídicos vs. Oficinas estatales}

Si bien las mujeres representan una mayoría de los abogados que se gradúan en las universidades chilenas, las abogadas son extremadamente escasas en posiciones a nivel de jefatura o de socios, especialmente en los estudios jurídicos más prestigiosos y las fiscalías. ${ }^{25}$ A pesar de que las abogadas han incrementado su porcentaje como

22 Después de salir de Chile, fui a España para realizar un estudio similar. Volví a Chile más adelante en el verano para realizar grupos de discusión. Estos estudios forman parte de una investigación más amplia multi-nacional sobre género y abogados.

23 Entrevista CH33, pp. 16-17.

24 Le pregunté a los estudiantes cómo esperaban que fuesen sus carreras, dónde trabajarían, si planeaban casarse o tener una pareja, si tenían planeado tener hijos, y si así era, quién de la pareja se tomaría tiempo fuera del trabajo para cuidar los niños, etc.

25 Un estudio de Latin Laweyer sobre los 10 estudios más grandes en Argentina, Brasil, Chile, Colombia, México y Perú, estableció que las mujeres representaban solo el 3,3\% de los socios en los grandes estudios jurídicos en Chile, el porcentaje más bajo de todos los países estudiados. Meldino (2009). 
socias de estudios de 2\% a 11\% entre 2006 y 2013, en 2016 Latin Lawyer determinó que Chile solo tenía un 9\% de mujeres socias en los principales estudios jurídicos, el porcentaje más bajo de todos los países latinoamericanos que fueron examinados. ${ }^{26}$

Tanto los entrevistados hombres como mujeres hicieron notar que las carreras de las mujeres se ven perjudicadas cuando se enfrentan a la "pared maternal". ${ }^{27}$ Muchas madres dejan de trabajar, se cambian de trabajos, o trabajan horas reducidas cuando tienen hijos. Una vez que una abogada rebaja su carga de trabajo para cuidar de sus hijos, normalmente no vuelve a trabajar jornada completa. Los trabajadores de jornada parcial tienen pocas posibilidades de convertirse en socios. Aunque una entrevistada volvió a trabajar con jornada completa y eventualmente se convirtió en socia del estudio, esta trayectoria es extremadamente inusual.

Sin embargo, hay una diferencia significativa entre los prospectos de las abogadas en estudios jurídicos y las oficinas estatales. En el sector público, según la mayoría de los entrevistados, las mujeres son tratadas con igualdad. Existen aparentemente dos excepciones a esta regla general: los fiscales y defensores públicos. Los entrevistados revelaron que las mujeres fiscales tienen dificultades para alcanzar posiciones de liderazgo y les asignan tareas menos prestigiosas - aquellas relativas a crímenes en contra de mujeres y niños-, mientras que los hombres persiguen los robos, homicidios, y otros delitos de alto perfil. Las defensoras públicas también se enfrentan a la resistencia de clientes, otros abogados y los jueces.

26 Mujeres en el derecho 2016: Altos y bajos (Chile en el 9\% es el más bajo de los 19 países analizados). Creswell y Rumsey (2014), pp. 5, 7-9. En contraste, el porcentaje de mujeres asociadas en la región es de 49\%, y de las mujeres socias es 20\%. Creswell y Rumsey (2014), p. 6. En Estados Unidos, las mujeres representan un $15 \%$ de los "equity partners" y $26 \%$ de los "non-equity partners". CRESWELL y Rumsey (2014), p. 10. Generalmente en Latinoamérica, pocas mujeres han sido miembros de comités gerenciales. Creswell y Rumsey (2014), p. 10. En el 2010, las mujeres representaban el 58\% de los abogados chilenos. Michelson (2013), pp. 1115-1119 (tabla de proporción de abogadas que son mujeres en más de 200 países). Al 58\%, Chile está más adelante que el promedio mundial de $36 \%$ y de Estados Unidos con 32\%, pero detrás de otros países sudamericanos como Brasil $(66 \%)$, Argentina (62\%) y Venezuela (61\%). Michelson (2013), pp. 1115-1119. Sin embargo, el porcentaje de abogadas no entrega información acerca del tipo de trabajo realizado o el porcentaje de mujeres socias. Aún más, las abogadas en Chile no tienen la misma cuota proporcional de poder político o en el estudio, o cargos en la academia. Azocar (2015), pp. 16-17 (destacando que las mujeres representan una proporción baja de socios en los estudios jurídicos, y solo cerca del 20\% de los profesores de derecho en la Universidad de Chile, y que son frecuentemente segregadas en las posiciones más bajas dentro de las Universidad y tienen baja representación en cursos como derecho penal); Organization of American States Inter-American Commission on Human Rights (2009) pp. 5-6 (concluyendo que, a pesar del nivel alto de educación logrado por las mujeres chilenas, ellas no obtienen los trabajos con mayores responsabilidades o mejores sueldos. "La Comisión detecta que la brecha salarial que separa a los hombres de las mujeres trabajando en los mismos cargos en Chile es verdaderamente alarmante; mientras más responsabilidad requiera un cargo, mayor es la brecha salarial").

27 La "pared maternal" es el término utilizado para referirse a las barreras que las mujeres enfrentan cuando se convierten en madres. Williams y Dempsey (2014), pp. 127-176. 
Las abogadas de otras oficinas estatales manifestaron satisfacción con sus carreras, pero la compensación estatal es baja ${ }^{28}$ especialmente más adelante en la carrera de los abogados ${ }^{29}$ Las juezas, especialmente a nivel de tribunales de primera instancia, dominan el poder judicial y han tenido éxito, pero las mujeres no han alcanzado números representativos en la Corte de Apelaciones de Santiago (la Corte de Apelaciones más prestigiosa) o la Corte Suprema. En las universidades, las profesoras son más numerosas que en el pasado, pero todavía están atrás considerablemente de sus colegas hombres. Sin embargo, hay una sensación de que las cosas se están moviendo en la dirección correcta en la judicatura y la academia.

\subsection{Responsabilidades familiares}

Los entrevistados hombres y mujeres universalmente concuerdan en que Chile es una sociedad tradicional que ve a las mujeres como encargadas de la casa y los hombres como proveedores, pero las opiniones disienten sobre cómo la norma cultural afecta a las abogadas en los lugares de trabajo. ${ }^{30}$ Algunos creen que las mujeres no son discriminadas en los lugares de trabajo, y que es solo cuestión de tiempo para que las mujeres compartan el mismo poder en los estudios jurídicos. Indican que las abogadas son contratadas en aproximadamente el mismo número que los abogados, y sostienen que algunas mujeres voluntariamente deciden dejar sus lugares de trabajo o reducir su carga de trabajo y oportunidades laborales cuando pasan a ser madres. ${ }^{31}$

Otros abogados defienden el derecho de los estudios a contratar hombres por sobre mujeres en edad fértil, porque una asociada mujer puede quedarse embarazada y tomarse el permiso desempeñando su cargo en el estudio. Estos empleadores reconocieron que consideran el rol de la mujer como encargada de la casa al decidir si contratarlas o ascenderlas. ${ }^{32}$ Argumentan que no es discriminación considerar la realidad estadística de que la mayoría de las mujeres chilenas se convierten en madres, se toman permisos largos, y vuelven a trabajar solo para quedarse embarazadas otra vez. ${ }^{33}$ Esta puerta giratoria, de acuerdo a algunos entrevistados, hace difícil que los empleadores puedan confiar en encargarles a las abogadas el mismo trabajo que sus contrapartes masculinas.

$28 \mathrm{Al}$ menos una entrevistada que trabaja en el sector público trabaja desde las 9 a.m. hasta las 9 p.m. diariamente. Véase Entrevista CH11, p. 11.

29 Entrevista CH 06, p. 5.

30 Un estudio reciente sobre participación femenina en el mercado laboral chileno concluye que la cultura machista afecta la participación de las mujeres en el mercado laboral. ConTreras y PLAzA (2010), p. 31 (las mujeres con mayor educación tienen mayor participación en el mercado laboral, mientras que las mujeres que han internalizado las posturas machistas tienen menores grados de participación). Desde luego, la historia de Chile - el gobierno socialista de Salvador Allende, que fue derrocado por las Fuerza Armadas y derivó en la dictadura de Pinochet, que duró entre 1973 y 1990- ha afectado los roles y derechos de las mujeres en Chile. MaGinley (2018); Power (2004).

31 Entrevista CH30, pp. 5-6, 21.

32 Entrevista CH27, pp. 5-7.

33 Entrevista CH07, p. 4; Entrevista CH53, p. 5. 
En las entrevistas de los estudios jurídicos, a las abogadas se les pregunta acerca de sus planes sobre tener hijos - un tema tabú en los departamentos de recursos humanos en Estados Unidos. ${ }^{34}$ Si bien la ley chilena prohíbe hacer estas preguntas, de acuerdo a los expertos, "es letra muerta". ${ }^{35}$ Los abogados responsables de contratación reconocen que el tema del matrimonio y los hijos se plantea regularmente tras bambalinas cuando se trata de postulantes mujeres; una discusión similar no ocurre en el caso de postulantes hombres de la misma edad. ${ }^{36}$

Los abogados más progresistas creen que considerar el potencial de tener hijos de una mujer al momento de considerar una contratación o un ascenso es discriminación de género dañina. Sostienen que muchas mujeres trabajan en horarios reducidos, pero que igualmente producen trabajo que es equivalente o mejor que el de sus contrapartes masculinas. A cambio de las horas reducidas, las madres renuncian a aumentos de sueldo, un porcentaje de sus remuneraciones, y oportunidades de ascender o subir a la categoría de socias. ${ }^{37}$

La cultura chilena tiene visiones tradicionales respecto a los roles de los hombres y las mujeres en el trabajo y la casa. Las mujeres se llevan la carga de trabajo en las responsabilidades familiares. En contraste, los hombres proveen del ingreso familiar. Tanto hombres como mujeres reconocen estas expectativas. Incluso quienes consideran estos límites como machistas, les es difícil escapar de la tradición en sus propias vidas. Todos los entrevistados concuerdan en que las madres que son abogadas hacen trabajos más relacionados con la casa, y exclusivamente se toman los permisos extendidos para cuidar de los hijos. Las madres con posturas igualitarias explican que sus cónyuges tienen trabajos más demandantes que el de ellas, o que los empleadores de los maridos no aceptarían la igual participación del padre en el cuidado de los hijos si ello implicaría reducción del tiempo de trabajo. ${ }^{38}$

Muchos padres reconocieron es más aceptado socialmente para las mujeres tomar el permiso parental que para los hombres, y que los empleadores y co-trabajadores juzgarían duramente a un padre que se tome un permiso extendido. ${ }^{39} \mathrm{Un}$ abogado dedicado a derecho laboral de la empresa señaló tres razones por las cuales los padres no se toman los permisos: 1. Las mujeres creen que es su responsabilidad, no la del padre; 2. Las madres amamantan a sus hijos; y 3. Los hombres son machistas, y no creen que debieran tomarse el permiso. ${ }^{40}$ Incluso si los padres quisieran

34 Discriminación por embarazo es discriminación sexual de acuerdo al derecho estadounidense. 42 U.S.C. Sec. 2000e (k); Entrevista CH37, p. 6 (destacando que se le preguntaba regularmente cuándo pensaba tener hijos).

35 Art. 194, inciso final, Código del Trabajo. Agradezco a Sergio Gamonal esta información. En su opinión, esta ley es "letra muerta".

36 Entrevista CH04, p. 10.

37 Entrevista CH03, pp. 3, 7, 11-15; Entrevista, pp. 13, 22-23.

38 Entrevista $\mathrm{CH} 03$, p. 5.

39 Entrevista CH05, p. 15-16.

40 Entrevista CH36, p. 8. 
tomarse el permiso, sería más fácil hacerlo en un empleo público que en uno privado. En el empleo público, hay mecanismos para reemplazar a los trabajadores con permiso; estos mecanismos generalmente no existen en los estudios jurídicos. Más aún, los hombres temen que sus empleadores y colegas los tratarán mal si se toman el permiso. ${ }^{41}$

Algunos padres también reconocen que las madres que vuelven a trabajar después del permiso post-natal siguen teniendo que cargar con las responsabilidades familiares. ${ }^{42}$ Ambos padres reconocen las dificultades en insistir sobre prácticas igualitarias en la familia y los lugares de trabajo, dada la macro-cultura, la meso-cultura de los abogados en Chile, y la micro-cultura de los estudios jurídicos particulamente. ${ }^{43}$

Tal como las madres de otros países, las madres chilenas han adaptado sus carreras para cumplir con las demandas culturales que les asignan responsabilidad primaria por sus familias. Las mujeres de clases más altas tradicionalmente han tenido la ayuda de mano de obra barata - mujeres que limpian, cocinan y se encargan del cuidado de los niños. ${ }^{44}$ Las chilenas profesionales que son madres se benefician con el trabajo de estas llamadas "nanas". Dado que las familias en Santiago tienden a vivir cerca unas de otros, los abuelos también se encargan bastante del cuidado de los niños. ${ }^{45}$ Muchos consideran como deficiente las salas cuna y jardines infantiles, y la mayoría de los padres entrevistados no los utiliza para sus hijos. ${ }^{46}$ Pero incluso la ayuda de los abuelos puede ser insuficiente para que las abogadas puedan cumplir con las demandas dobles de una carrera legal de jornada completa y una familia. Especialmente los trabajos en grandes estudios privados e internacionales, y la persecución penal y defensa requieren largas jornadas de trabajo.

Si bien un porcentaje alto de abogadas - sean madres o no- parece enfrentar dificultades relacionadas con el género en los estudios jurídicos y las oficinas de fiscalías y defensorías públicas, las entrevistas sugieren que el embarazo y la maternidad exacerban los problemas de las abogadas. Muchas mujeres jóvenes que esperan tener hijos señalan que será imposible para ellas cumplir sus responsabilidades como abogadas y madres. Como resultado de ello, planean dejar los estudios, o moverse a consultoras y otros trabajos, o intentar trabajar con jornada parcial. ${ }^{47}$

41 Entrevista CH36, p. 8.

42 Entrevista CH36, p. 15.

43 Entrevista CH03, p. 5; CH05, pp. 15-16.

44 Rodriguez (2007).

45 Entrevistas CH02, p. 12; CH03, p. 9; CH04, p. 12; CH06, p. 12.

46 Un juez considera que el Estado debiera garantizar un mejorado cuidado de los hijos, de manera tal que las madres puedan prosperar en su trabajo. Entrevista CH51, p. 12.

47 Entrevista CH22, pp. 13, 23. 
Desgraciadamente, muchos estudios jurídicos no tienen una carrera para llegar a ser socios, e incluso aquellos que la tienen, generalmente no promueven a socios los asociados que han trabajado en jornada parcial. ${ }^{48}$ Hay unas pocas excepciones. Unos pocos estudios han permitido a mujeres trabajar con jornada parcial por un tiempo, y luego regresar a condición de jornada completa y ser consideradas para ser socias.

\subsection{No es solo sobre la maternidad}

Dada la fuerte cultura tradicional de la división del trabajo basado en el género, incluso las abogadas que no toman el camino tradicional sufran con las expectativas de que van o debieran tener familias. ${ }^{49}$ Muchos entrevistados creen que el estereotipo de que las mujeres no son buenos líderes perjudica a las abogadas que buscan ascender en sus cargos. ${ }^{50}$ Este resultado es consistente con la investigación en Estados Unidos sobre los estereotipos de las mujeres como líderes. Cuando las mujeres infringen normas prescriptivas - por ejemplo, las mujeres no debieran ser agresivas y debieran ser cálidas y amistosas- son juzgadas duramente que los hombres por el mismo comportamiento. ${ }^{51}$

Muchos entrevistados concuerdan en que culpar a la maternidad por el fracaso de las mujeres para avanzar es un engaño. Las mujeres no deciden trabajar en cargos peor pagados o en trabajos menos interesantes porque son madres, sino que las demandas laborales y familiares hacen que sea imposible para ellas hacer algo distinto. Estos entrevistados afirmaron que incluso una mujer soltera que no tiene hijos enfrenta dificultades para alcanzar las esferas altas de los estudios más prestigiosos y algunas oficinas estatales. ${ }^{52}$ Los empleadores del derecho subvaloran el trabajo de la mujer y su habilidad para liderar. Estas actitudes afectan las tareas que se les asignan, y las abogadas desarrollan trabajos de menor importancia que sus colegas hombres de la misma condición. ${ }^{53}$ Un abogado en sus cuarenta atribuye las desigualdades a la opinión chilena de que el derecho es una disciplina masculina. ${ }^{54}$

La cultura chilena en general todavía está imbuida en los roles de género. Las abogadas en alguna medida son consideradas externas, y se espera de ellas que se

48 Entrevista $\mathrm{CH} 19$, p. 13 (asociada cree que cuando tenga hijos en este pequeño estudio jurídico podrá rebajar la cantidad de trabajo y después llegar a ser socia, pero que esto no sería posible en un estudio más grande).

49 Entrevistas CH15, pp. 8, 12 - 13; CH39, pp. 5-6, 8, 10; CH05, p. 10.

50 Entrevista CH40, p. 12 (académica que me dijo que otros colegas hombres piensan que las mujeres son inferiores a los hombres); CH33, pp. 14-15, 18; CH05, pp. 10-11; CH18, p. 4; CH04, p. 4; CH16, pp. 17-18.

51 MaGinley (2009), pp. 109-12.

52 Entrevista CH33, pp. 14, 18.

53 Entrevista CH33, pp. 4, 11-12, 14, 18; Entrevista CH20, p. 11; Entrevista CH49, pp. 4-5.

54 Entrevista CH42, p. 9. 
acomoden a los estereotipos de trabajo duro y organizado. Incluso si no tienen interés alguno en ser madres, las abogadas son juzgadas a través del lente de los roles que se espera de las mujeres. Las mujeres que deciden no tener hijos son consideradas como raras..$^{55}$

Las abogadas exitosas notan un tratamiento distinto. Una jefa de división de un estudio que litiga casos sofisticados para grandes empresas internacionales, trabajando horas reducidas, cree que ella es tratada como una ciudadana de segunda clase. ${ }^{56}$ Asimismo, una mujer supervisora en una oficina importante de fiscalía señala que sus colegas hombres frecuentemente esperan que ella haga trabajo de "secretaria" cuando trabajan casos en conjunto. ${ }^{57}$

Todas las mujeres, incluso aquellas que no quieren casarse o tener hijos, parecen ser tratadas de manera similar, aunque las madres puede que tengan particularmente un mal tratamiento. ${ }^{58} \mathrm{Un}$ abogado de mediana edad que en el pasado trabajó como fiscal afirmó que:

Debo insistir nuevamente en que [la maternidad] no es el tema; el tema en nuestro caso todavía es la cultura que gobierna los ambientes de trabajo, donde los puestos importantes siempre son ocupados por hombres; creo que la mejor prueba de esto ... es que [en Chile] hay muchos jefes hombres incompetentes, y en general, pocas jefas mujeres incompetentes. ${ }^{59}$

El que las mujeres que no tienen hijos sean también consideradas menos competentes que los hombres puede ilustrar el concepto de "competencia de género" o "expertise de género". Dado que el derecho es considerada una disciplina masculina, y que solo ciertos tipos de áreas del derecho como el derecho de familia son consideradas como femeninas o dentro de las competencias de las mujeres, las mujeres con frecuencia serán tratadas de manera distinta, porque ellas supuestamente carecen de la expertise masculina para ser consideradas como buenas abogadas en una disciplina masculina. ${ }^{60}$

55 Entrevista CH39, p. 5.

56 Entrevista CH03, p. 15.

57 Entrevista CH49, pp. 4-5.

58 Entrevista CH49, p. 10; Entrevista CH33, pp. 14, 18.

59 Entrevista CH33, p. 18.

60 AzOCAR y Ferree (2015), pp. 855-857 (explicando que las posturas acerca de competencia y expertise son basadas en género, y que el derecho, especialmente áreas prestigiosas y respetadas del derecho como el derecho penal son masculinas). 


\subsection{La Iglesia Católica y el Opus Dei}

Muchos entrevistados mencionaron el rol de la Iglesia Católica, y más específicamente, el Opus Dei ${ }^{61}$ en la fijación de normas culturales. Muchos abogados que trabajan en Santiago son graduados de la Universidad de Los Andres, universidad privada que está vinculada con el Opus Dei. ${ }^{62}$

Algunos estudios jurídicos están dominados por socios que son miembros del Opus Dei. En estos estudios, dado el énfasis en la familia, hay más respeto a las mujeres, y más apoyo al rol de las mujeres como madres. Por otra parte, las mujeres se sienten constreñidas. Una abogada joven dijo que se le advirtió que no mencionara en el trabajo el asunto de vivir con un novio (y no estar casada con él). ${ }^{63}$ Otra, que fue alumna de la Universidad de los Andes, dijo que las mujeres de edad más avanzada en un estudio jurídico con socios del Opus Dei le llamaron la atención por su vestimenta "inapropiada". ${ }^{64}$ Ella dijo que las abogadas en general eran más machistas que los abogados, y que si una mujer no casada era activa sexualmente, la otra mujer la consideraría una "puta" ${ }^{65}$

Una ex asociada de un estudio dominado por el Opus Dei estaba de acuerdo: le gustaba el sistema de selección meritocrático del estudio, ${ }^{66}$ y valoraba sus supervisores hombres, pero ella creía que los abogados "paternales" tenían una visión machista y protectora de la mujer. Las abogadas no se llevaban bien con sus superiores mujeres que imponían reglas sobre las asociadas jóvenes ${ }^{67}$ y que las trataban más severamente que a los asociados hombres. ${ }^{68} \mathrm{La}$ entrevistada concluía que estas dinámicas hacen muy difícil para una mujer avanzar en el estudio Opus Dei, y las mujeres se vuelven muy competitivas entre sí. ${ }^{69}$ Como consecuencia de ello, ella dejó el estudio. ${ }^{70}$

61 El Opus Dei es una "sociedad secreta" fundada por un sacerdote español, Josemaría Escrivá de Balaguer el 2 de octubre de 1928, cerca de Madrid, España. Walsh (2004), pp. 10, 13. Sus miembros incluyen numerarios masculinos célibes, que viven juntos como si fuesen sacerdotes, y realizan trabajo apostólico. Las numerarias femeninas también son célibes, y son responsables del trabajo doméstico en los centros masculinos de numerarios; miembros agregados tienen las mismas reglas que los numerarios, incluyendo el celibato y el trabajo apostólico, pero viven con sus familias. Los supernumerarios pueden casarse y vivir con sus familias. WALSH (2004), pp. 89-90. El rol de las mujeres es confuso dentro del Opus Dei. Si bien algunas mujeres se les asigna trabajo doméstico de los numerarios, otras tienen carreras profesionales. Mönckeberg (2016). La organización tiene valores muy conservadores; se opuso al esfuerzo de Vaticano II de modernizar la Iglesia. WaLSH (2004), p. 62. El Opus Dei tiene una visión tradicional acerca de los roles de las mujeres y los hombres. WALSH (2004), pp. 109-110.

62 Entrevista CH31, p. 5. Muchas de las mujeres que trabajan en la Universidad de los Andes son numerarias. Entrevista CH31, p. 5.

63 Entrevista CH12, pp. 15-16.

64 Entrevista CH44, p. 5.

65 Entrevista CH44, p. 6.

66 Entrevista CH21, p. 7.

67 Entrevista CH21, p. 11.

68 Entrevista CH21, p. 12.

69 Entrevista CH21, p. 11.

70 Entrevista CH21, p. 12. Un socio administrador hizo notar que en un estudio Opus Dei en Santiago hay cuarenta abogados con solo tres abogadas. Entrevista CH53, p. 4. 
Una Universidad doctrinariamente menos conservadora que la Universidad de los Andes es la Pontificia Universidad Católica, que tiene profesores de distintas posturas en el espectro político. ${ }^{71}$ Pero a pesar de los profesores relativamente moderados en la Universidad Católica, la Iglesia misma adopta posturas conservadoras sobre asuntos sociales, y operan colegios católicos de elite. Su influencia es conservadora y de clases. Por lo cual, la religión y la clase social parecen entremezclarse. ${ }^{72}$

\subsection{Estructura de clases}

En Chile, la clase social impone una carga pesada sobre los externos, y le otorga ventajas importantes a los internos. Muchos entrevistados creían que la clase social puede ser incluso más importante que el género al contratar abogados, especialmente para trabajar en los prestigiosos estudios jurídicos en Santiago. ${ }^{73}$ Un alto porcentaje de estudiantes de derecho que se gradúan de importantes facultades de derecho fueron a colegios privados, algunos de ellos operados por organizaciones católicas. Los abogados chilenos universalmente explican que el colegio, mucho más que la universidad en la que uno estudia, determina si se abrirán las puertas para trabajar en los mejores estudios jurídicos. ${ }^{74}$ Sin embargo, el que un abogado haya estudiado en un colegio particular es menos importante para trabajar en una oficina estatal. ${ }^{75}$

71 Actualmente, la Universidad ha prohibido a los hospitales y clínicas pertenecientes a la red de la Universidad a realizar abortos. Esto ha llevado a protestas y desacuerdos entre la comunidad universitaria. SEgOvia (2017).

72 Entrevista CH03, p. 14.

73 El colegio privado al cual una atiende es un tema al momento de la contratación en estudios jurídicos prestigiosos, pero no para puestos judiciales. Entrevista CH25, p. 14. El estudio tradicional era la institución de una familia, y los abogados eran "caballeros" que provenían de la clase más alta. Dezalay y Garth (2002), pp. 18, 21-22. Durante el regimen de Pinochet, esta tradición se vio enfrentada a un grupo de "tecnócratas" altamente educados, que fueron educados frecuentemente por la Universidad de Chicago en economía neoliberal. Estas nuevas y jóvenes personas tenían expertise económica y eran capaces de resistir a las clase más alta de "caballeros" abogados porque eran jóvenes, agresivos, mejor educados y más interncionales en su enfoque. Azocar y FerreE (2015), pp. 847-848. Tanto los caballeros abogados como los “tecnócratas" que estudiaron economía enfatizaban una versión del derecho varonil y masculina, aunque hayan sido distintos entre sí.

74 Weissman (2016) (atender a uno de ocho colegios aumenta significativamente la probabilidad para un chileno de estar en el 1\% de los ingresos más altos). La mitad de los gerentes en Chile de las 100 empresas más grandes se graduaron de cinco colegios en Santiago; "La mitad" (2013). Entrevista CH38, p. 11 (los estudios grandes contratan personas de ciertos colegios porque saben quiénes son los padres del postulante; si un abogado viene de otras zonas, es muy difícil obtener un trabajo en un estudio grande en Santiago); Ramirez (2016) (los colegios privados en Chile son caros, aceptan solo estudiantes con resultados altos en las pruebas de clases altas, y una vez en el colegio privado, los estudiantes no tienen acceso a otros estudiantes de clases más bajas); Toro (2014) (una de las familias más ricas en Chile envía sus hijos al prestigioso Grange School y a una universidad de negocios en Estados Unidos).

75 Entrevista CH06, pp. 2-3. 
Los entrevistados afirmaron que los estudios jurídicos importantes contratan abogados hombres mediocres de familias conocidas, ${ }^{76}$ pero que las mujeres que se contratan deben ser excepcionales. Los sujetos entrevistados se quejaban porque el concepto de mérito solo surgía cuando las mujeres comenzaban a postular para trabajos en carreras dominadas por hombres; "mérito" es utilizado para alejar a mujeres, y no a hombres, de cargos o ascensos. ${ }^{77}$ Tal como una destacada abogada señaló, "tendremos igualdad de género de verdad cuando las mujeres mediocres empiecen a ser jefas". ${ }^{78}$

Del mismo modo, el nombre de una persona o forma de hablar que revele orígenes en clases bajas puede descalificar a postulantes para puestos en los estudios jurídicos más prestigiosos. ${ }^{79}$ Los socios no quieren contratar postulantes de clase baja, señalan, porque sus clientes no se sentirán cómodos con ellos. ${ }^{80}$

Sin embargo, la socia de un gran estudio internacional hizo notar que las prácticas están cambiando en los estudios grandes. En estos estudios, señaló, a diferencia de los viejos tiempos, la contratación es meritocrática, pero reconoció que algunos colegios otorgan una ventaja significativa porque les enseñan a los niños un segundo idioma, y cómo expresarse bien en español. ${ }^{81}$

Si bien algunas de las restricciones sociales son basadas en género, los sujetos dijeron que los hombres también sufren como resultado del sistema rígido de clases sociales, ${ }^{82}$ pero la clase social se combina con el género para tener un efecto particularmente negativo sobre las oportunidades de las mujeres, ${ }^{83}$ porque las clases más altas en Chile siguen posturas muy tradicionales relativos a los roles de género apropiados.

76 Entrevista CH49, p. 20; CH50, pp. 18-19.

77 Entrevista CH49, p. 21.

78 Entrevista CH49, p. 21.

79 Un artículo criticando la conciencia de clases en Chile se enfoca en las familias de las clases más ricas que pasan sus vacaciones en el exclusivo balneario de Zapallar, y les exigen a sus trabajadoras domésticas que vistan uniformes perfectamente planchados con delantales, mientras deben cuidar de sus hijos en la playa. UGarte (2011).

80 Entrevista CH38, p. 4. Sin embargo, hay una exitosa abogada excepcional que tiene apellidos árabes. Entrevista CH38, p. 4.

81 Entrevista CH 52, pp. 17-18.

82 Entrevista CH37, p. 8; Entrevista CH42, pp. 12-13.

83 Entrevista CH 03, p. 7. 


\subsection{Estructuras tradicionales de los lugares de trabajo jurídicos}

Algunos sostienen que los chilenos no trabajan eficientemente y que su productividad es baja. ${ }^{84}$ Aun así, los chilenos regulares trabajan desde temprano en la mañana hasta al menos 7 u 8 p.m. Muchos se toman un almuerzo largo y luego vuelven al trabajo. En los estudios jurídicos, la gran mayoría de los abogados trabaja al menos hasta las 7 u 8 p.m.; en los grandes estudios jurídicos, muchos trabajan regularmente hasta las 11 p.m. o más tarde. ${ }^{85}$ Dado que este es un horario muy duro, muchos abogados, especialmente las mujeres con hijos, dejan los grandes estudios. ${ }^{86}$

$\mathrm{Al}$ parecer, un abogado eficiente podría terminar de trabajar más temprano, pero los chilenos valoran el tiempo presencial en el trabajo por sobre los logros. ${ }^{87} \mathrm{Un}$ abogado explicaba que los empleadores preferirían contratar abogados hombres que están disponibles hasta tarde en la noche por sobre mujeres que tendrían su trabajo listo para poder irse a sus casas para estar con sus hijos, incluso si los hombres se dedicaran a leer las noticias deportivas en el trabajo durante las noches. ${ }^{88}$

La jornada laboral chilena - un largo día de trabajo con un largo almuerzo, llegada tarde a la casa y una cena tarde-- refuerza el rol de género tradicional de los hombres como proveedores de las mujeres, y estas últimas como encargadas de la casa. La oficina de abogados está organizada en torno a los roles tradicionales y los horarios de los hombres que se benefician de las mujeres que cuidan a los niños y cumplen las otras responsabilidad familiares. Esto es particularmente dañino para las carreras de las abogadas que son madres o que se encargan de la casa.

Por ejemplo, abogadas que trabajan para un ministerio explicaban que las comisiones de gobierno programaban, sin aviso previo, reuniones entre las 7 y 10 p.m. Cuando esto ocurre, las madres jóvenes deben ingeniárselas para conseguir alguien que pueda cuidar los niños. ${ }^{89}$ Una reunión nocturna espontánea es un "tsunami" para una madre soltera: debe arreglársela para que su cuidadora lleve a su hijo a la casa de sus padres, para asegurarse que allí ellos lo cuidarán. ${ }^{90}$

Incluso una madre que está casada con el padre de sus hijos enfrenta serias dificultades debido al demandante trabajo del marido, y la expectativa de sus colegas de que tiene apoyo doméstico. ${ }^{91} \mathrm{Su}$ madre cuida a los niños con poca anticipación, cuando es necesario. ${ }^{92}$ Sin la ayuda de su madre, ella estaría en problemas.

\footnotetext{
84 Véase, por ejemplo, Entrevista CH43, p. 14.

85 Entrevista CH03, p. 7; CH44, p. 8; CH10, p. 7, CH22, pp. 10-11.

86 Entrevista CH21, p. 13.

87 Entrevista CH43, p. 14; CH03, pp. 11, 15.

88 Entrevista CH43, p. 14.

89 Entrevista CH43, p. 9.

90 Entrevista CH43, p. 13.

91 Entrevista CH43, pp. 13-14.

92 Entrevista CH43, p. 14.
} 


\subsection{El cambiante mercado jurídico y la respuesta de la gente más joven}

Los grupos de discusión de estudiantes destacaron que la práctica del derecho ha cambiado. El derecho es una carrera mucho más competitiva de lo que había sido antes. ${ }^{93}$ Los estudios jurídicos hoy en día son jerárquicos, pero los estudiantes esperan poder recontextualizar el trabajo. ${ }^{94}$ No tienen la expectativa de trabajar por 30 años en un solo lugar, pero esperan poder desarrollar habilidades trabajando en Chile y otros países, realizando cursos de postgrado, viajando, y aprendiendo idiomas para poder competir en el mercado laboral mundial. ${ }^{95}$ Dado que pertenecen a la primera generación que creció utilizando Internet, ellos pueden trabajar en diversos contextos de manera muy eficiente. ${ }^{96}$ Estas habilidades, combinadas con la naturaleza cambiante del trabajo, debiera incrementar la flexibilidad en lo que hacen, cuándo lo hacen, y cómo lo hacen. La flexibilidad generará más oportunidades para adquirir más cualidades, desarrollar sus intereses, y criar sus familias de modos más igualitarios mientras desarrollan sus carreras.

Los estudiantes creen que los miembros de las generaciones más viejas son más machistas que ellos, y los estudiantes son optimistas de que su generación cambiará la sociedad. Sin perjuicio de ello, advierten que Chile es un país basado en las clases sociales, y que los líderes de los estudios jurídicos de clases altas les enseñan discriminación de clase a sus hijos, quienes en el futuro pueden ser los líderes de los estudios. Los estudiantes señalan que es necesario acabar con la discriminación de clases, de manera tal que Chile se convierta en un país igualitario en términos de clase y género. ${ }^{97}$

\section{DEREGHO, GULTURA Y SOLUGIONES ALTERNATIVAS}

\subsection{Cambiando los requisitos legales y las respuestas de género}

El derecho es moldeado por la cultura. ${ }^{98}$ Tan pronto como se acabó la dictadura, la democracia emergió a partir de una demanda reprimida por libertad e igualdad. Se dictaron entonces leyes sobre permisos parentales y otras leyes favorables a la familia.

93 Grupo de Discusión, CH68-72, p. 2.

94 Grupo de Discusión, CH68-72, p. 3.

95 Grupo de Discusión, CH68-72, pp. 2-3.

96 Grupo de Discusión, CH68-72, p. 6.

97 Grupo de Discusión, CH68-72, pp. 8-9; 14-15.

98 Las relaciones entre el derecho y la cultura son complicadas. Incluso las definiciones mismas de cultura y cultura jurídica son discutibles. Derecho y cultura no son ámbitos distintos que solo marginalmente se relacionan una con la otra. MEzeY (2001) pp. 35-38 (concibiendo la interacción entre el derecho y la cultura como "una síntesis inestable entre las dos, formada por un reciclaje continuo y rearticulación de los significados jurídicos y culturales”). 
Este estudio sugiere que estas reformas tienen efectos mixtos sobre las oportunidades de las abogadas. Las madres debieran tener permisos maternales que les permitan recuperarse de los partos, desarrollar el apego con sus recién nacidos, y establecer una rutina de alimentación que se beneficie tanto al bebé como a la madre. Pero una ley que solo establece el permiso obligatorio para la madre refuerza la norma cultural de que no corresponde al rol del padre cuidar de los niños. Otras leyes, como la del fuero maternal y el requerir un mínimo de empleadas mujeres para las empresas parecen también perjudicar a las carreras de las mujeres. Estas normas hacen que sea más caro y/o inconveniente para los empleadores contratar mujeres. Más aun, dada la cultura y la realidad estadística de que la mayoría de las mujeres cuidan de sus hijos, todas las mujeres jóvenes son "madres potenciales". Si bien los empleadores mencionan el costo de tener que pagar la diferencia entre el subsidio estatal y la remuneración del trabajador cuando tiene permiso, ellos parecen estar más preocupados sobre la posible naturaleza consecutiva de tiempo no trabajado en la oficina. Las mujeres chilenas rara vez tienen un solo hijo, dicen, y el tiempo de los permisos puede agregar años de trabajo perdido y de interrupciones en el desarrollo de sus carreras. ${ }^{99}$

Los empleadores reconocen que las reformas que favorecen las familias los hace ser cautelosos para contratar mujeres en edad fértil. Las leyes fueron dictadas para ayudar a las mujeres y familias, y han sido exitosas al otorgar permisos maternales pagados largos. Sin embargo, combinadas con normas culturales segregan estrictamente los roles de las mujeres y los hombres, las leyes pueden provocar consecuencias no queridas en este grupo demográfico de perjudicar las carreras de las mujeres, y no eliminar la tradicional distancia entre los padres y sus hijos más pequeños. Esto no necesariamente significa que las leyes no le hayan servido a la gran mayoría de las mujeres en trabajos donde las remuneraciones no exceden el tope máximo de subsidio, donde los reemplazos no son difíciles de encontrar, o en los casos en que las interrupciones en la carrera no tienen el mismo precio. Pero incluso en estos trabajos, las leyes podrían mejorar. El defecto de la ley en cuanto a no incluir a los padres en el fuero, al no requerir que todos los empleadores con más de 20 trabajadores (independiente del número de trabajadoras mujeres) subsidien el cuidado infantil, y el requerir a los padres hacer uso del permiso post-natal provoca costos diferenciales significativos entre la contratación y promoción de hombres y mujeres en trabajos relacionados con el derecho y del mismo modo en otros trabajos. Las leyes debieran considerar abordar estas debilidades.

99 Entrevista CH53, p. 5. En realidad, las mujeres tienen un promedio de 1.8 niños por mujer, virtualmente la misma proporción que las mujeres en Estados Unidos. Central Intelligence Agency. 


\subsection{Meso-cultura: Abogados, masculinidad y tradición}

La meso-cultura de los abogados es tradicional y masculina. ${ }^{100}$ Los estudios jurídicos en Chile, como en Estados Unidos, se basan en la conducta masculina, "abogadil" de trato agresivo, adversarial, y de trabajo duro que fija los roles de los hombres como proveedores y las mujeres como encargadas de la casa. ${ }^{101}$

Especialmente en los estudios grandes, las expectativas de trabajo duro y jornadas largas, la necesidad de responder rápido a clientes sin demoras y el sacrificar la vida personal para la "causa" del estudio es una forma neoliberal de practicar derecho. ${ }^{102}$ La jornada laboral asume que un abogado no tiene responsabilidades familiares y que tiene una persona en casa que se preocupa de su familia y casa.

Los estudios jurídicos chilenos elaboran sus jornadas y expectativas en torno al estilo de vida del abogado hombre tradicional, que tiene pocas obligaciones familiares durante la semana que no sean tener un buen salario. Las abogadas con responsabilidades parentales trabajan duro y se toman pocos descansos en el trabajo, para poder terminar su trabajo y poder ir a sus casas para estar con sus hijos. En la medida que estas madres son consideradas menos efectivas solamente porque los hombres pasan más tiempo en la oficina, es el estilo de vida de los hombres lo que determina exactamente lo que es el trabajo.

Los estudios jurídicos son el hábitat del trabajo del hombre y de las amistades homoafectivas entre colegas hombres que forjan la conexión y la autoestima masculina. ${ }^{103}$ En gran medida las abogadas son excluidas de esta fraternidad. La pregunta es en qué medida los almuerzos largos y las jornadas laborales extendidas forman parte del trabajo mismo. Los sujetos entrevistados, tanto hombres como mujeres, discrepan sobre esta materia. Por cierto, si en el almuerzo se habla de trabajo, todos los abogados involucrados en el trabajo debieran estar presentes, pero si el propósito de los almuerzos largos es mantener relaciones homoafectivas entre los hombres que solo marginalmente se relacionan con el trabajo, la presencia en estos eventos no debiera determinar si un asociado hombre o mujer logra conseguir el éxito. Las madres reclaman por lo que ellas ven como tiempo perdido en los largos almuerzos, mientras que los hombres con pocas responsabilidades familiares señalan que el almuerzo es un momento importante para discutir sobre el trabajo con colegas o reunirse con clientes. Dependiendo de la situación, ambos pueden estar en lo correcto, pero los estudios jurídicos generalmente consideran el tiempo presencial como más valioso de lo que probablemente debieran considerar.

100 MaGinley (2016), pp. 158-170.

101 MaGinley (2016), pp. 160-169.

102 Collier (2013), pp. 426-432.

103 Kimmel (2004), pp. 81-91 (los hombres prueban su masculinidad a través de relaciones homosociales; las relaciones entre hombres son peligrosas porque pueden ser interpretadas como homosexuales, con lo cual conducentes a conductas hiper-masculinas). 
Muchos estudios ven a las mujeres como más organizadas, mejores para trabajar. Aunque estas actitudes parecer ser cumplidos, a las mujeres se les asigna trabajos de menor nivel y trabajo organizacional, pero no se las ve como líderes o socias potenciales, especialmente si y cuando se convierten en madres. Los estudios se benefician de las mujeres que trabajan duro sus primeros años, tienen hijos y luego renuncian al trabajo definitivamente o trabajan bajo una jornada reducida de horas. En muchos casos, la jornada reducida se traduce en una remuneración baja, aun cuando puede que la mujer logre completar las mismas tareas que sus contrapartes de jornada completa. Aún más, en la mayoría de los casos, el trabajo en jornada parcial le impide a la madre llegar a ser socia. ${ }^{104}$

Los estudios jurídicos han hecho algunos acomodos que no son requeridos por ley. Permitirle a una madre trabajar en una jornada reducida ofrece ventajas para el estudio, porque a la mujer se le paga menos por la misma cantidad de trabajo, y la jornada reducida es caracterizada como trato preferencial o beneficioso para la mujer, cuando en realidad, dado que deja fuera a la mujer para considerarla para ser socia o impide su ascenso, puede ser trato discriminatorio contra las mujeres. ${ }^{105}$

\section{CONGLUSIÓN: LA GULTURA Y EL DEREGHO TRABAJANDO JUNTOS}

Los entrevistados sugieren que la cultura es generalmente determinante a la hora de analizar cómo el derecho opera en la práctica. En Chile, la cultura afecta la interpretación y operación de las leyes que regulan los derechos de las mujeres como abogadas. Las abogadas frecuentemente sufren discriminación de género, aunque la ley lo prohíba. A las mujeres se les asignan trabajos y beneficios sobre la base de estereotipos, y las expectativas de que las mujeres jóvenes van a ser madres afectan la contratación y ascensos de las abogadas jóvenes. El permiso post-natal es progresista al permitir a las madres darle a los padres de sus hijos tres meses de su permiso post-natal, pero los padres rara vez se toman el permiso, debido a la desaprobación de sus empleadores y colegas. Por otra parte, dado que la ley misma enfatiza los derechos de la madre para el permiso, el fuero, y el subsidio para el cuidado infantil, al menos estas normas reflejan sesgos culturales y estereotipos, según los cuales es responsabilidad de la madre y no del padre cuidar de los niños. En tanto estas leyes puedan reflejar estos sesgos, este proyecto demuestra que debieran considerarse reformas legales.

La ley en Chile prohíbe la discriminación al contratar bajo el Código del Trabajo, pero los mecanismos probatorios y los remedios son inferiores a los contemplados por el procedimiento de tutela laboral. Desgraciadamente, la tutela laboral no protege a los postulantes de trabajos de discriminación. Esta desprotección, combi-

104 Solo una mujer que entrevisté que tuvo una jornada laboral reducida logró ser después socia de un estudio. Entrevista CH52, pp. 2-3.

105 Las soluciones van más allá del ámbito de este artículo. Para una discusión acerca de potenciales soluciones públicas y privadas, véase MaGinLey (2018). 
nada con las leyes de permisos parentales, crea un desincentivo para contratar mujeres jóvenes en edad fértil, al menos aquellas que son abogadas. ${ }^{106}$

Sin embargo, las respuestas al derecho y/o la cultura no ocurren en línea recta. Sin una disposición cultural, leyes más progresistas no serán dictadas. Una vez dictadas, una ley puede ser ignorada, inefectiva o tener consecuencias no deseadas. O la ley puede tener un efecto modernizante sobre la cultura. La solución pública es educar a la población, al mismo tiempo que los legisladores trabajan en la legislación. Después que una nueva legislación se promulga, los educadores y legisladores debieran estudiar los efectos de la ley, tanto positivos como negativos, y reaccionar conforme a ello. ${ }^{107}$

$106 \mathrm{El}$ art. 194 prohíbe preguntar por embarazo en una entrevista, pero esta norma es ignorada. Agradezco a Sergio Gamonal por haberme explicado esto.

107 Para una discusión acerca de potenciales reformas legislativas, así como también cambios privados que los estudios de abogados debieran realizar para tener una fuerza laboral más igualitaria, véase MaGinley (2018). 


\section{BIBLIOGRAFÍA CITADA}

Azocar, María José. (2015). "Experts in Law: Legal Profession, Gender, and Judicial Reforms in Chile", Revista de Derecho, Vol. 28, PP. 9-29.

Azocar, María José and Ferree, Myra Marx. (2015). "Gendered Expertise", Gender E Society, Vol. 29, pp. 841-862.

Biernacki, Patrick and Waldorf, Dan. (1981). "Snowball Sampling: Problems and Techniques of Chain Referral Sampling”, Sociological Methods \& Research, Vol. 10, pp. 141-163.

Bonnefoy, Pascale and Londoño, Ernesto (2017). https://www.nytimes. com/2017/12/17/world/americas/chile-presidential-election.html?_r=0.

Central Intelligence Agency, The World Factbook, en https://www.cia.gov/library/ publications/the-world-factbook/fields/2127.html.

Collier, Richard (2013). "Rethinking Men and Masculinities in the Contemporary Legal Profession: The Example of Fatherhood, Transnational Business Masculinities, and Work-Life Balance in Large Law Firms", Nevada Law fournal, Vol. 13, pp. 410-437.

Contreras, Dante y Plaza, Gonzalo (2010). "Cultural Factors in Women's Labor Market Participation in Chile", Feminist Economics, Vol. 16, pp. 27-46.

Creswell, Rosie y Rumsey, Lulu (2014). "Women in Law 2013”, Latin Lawyer. Vol. 12 , pp. 5, $7-9$.

Dides, Claudia y Maulhardt, Tessa (2015). "A Debt of Democracy: Abortion in Chile", en http://churchandstate.org.uk/2015/12/a-debt-of-democracy-abortion-in-chile/.

El Mostrador (2017). "El rojeria de luto: Piñera Gana en Segunda vuelta", en HTTP://WWW.ELMOSTRADOR.GL/NOTICIAS/PAIS/2017/12/17/EL-ROJERIO-DE-LUTO-PINERA-GANA-EN-SEGUNA-VUELTA/.

Gamonal C., Sergio (2013). ABC del Contrato de Trabajo (Editorial Libromar).

Gamonal C., Sergio (2005). "Discriminación femenina y part-time o trabajo tiempo parcial", Revista Laboral Chilena, Vol. 1, pp. 69-74.

Hepburn, Stephanie y Simon, Rita J. (2006). Women's Roles and Statuses the World Over (Lexington Books).

KImmeL, Michael S. "Masculinity as Homophobia: Fear, Shame, and Silence in the Construction of Gender Identity", en Rothenberg, Paula S. (ed.) Race, Gender, and Class in the United States: An Integrated Study (2004) (6ta edición), pp. 81-91. 
Mander, Benedict. "Chile pension reform comes under world spotlight", en https:// www.ft.com/content/b9293586-7680-11e6-bf48-b372cdb1043a.

Marshall, William N. (1996). "Sampling for Qualitative Research”, Family Practice, Vol. 13, pp. 522-525.

MaGinley, Ann C. (2018). "Gender, Law, and Culture in the Legal Workplace: A Chilean Case Study”, Arizona Law Review, Vol. 60 (por aparecer).

MaGinley, Ann C. (2016). Masculinity at Work: Employment Discrimination Law through a Different Lens (NYU Press).

MaGinley, Ann G. (2015): "Young v. UPS, Inc.: A Victory for Pregnant Employees?", en http://www.hamilton-griffin.com/2015/03/29/guest-blog-annmcginley-young-v-ups-inc-a-victory-for-pregnant-employees/.

MaGinley, Ann C. (2009). "Reproducing Gender on Law School Faculties", Brigham Young University Law Review, Vol. 2009, pp. 99-155.

Meldino, Emiliano (2009). "Women Lawyers' Organization Launches in Chile”, en http://www.citybarjusticecenter.org/wp-content/uploads/pdf/LL\%20WIP_ March\%202011_Womens\%20lawyer\%20organization $\% 20$ launches $\% 20$ in $\% 20$ Chile.pdf.

Mezey, Naomi (2001). "Law as Culture", Yale Journal of Law $\mathcal{E}$ the Humanities, Vol. 13, pp. 35-67.

Michelson, Ethan (2013). "Women in the Legal Profession, 1970-2010: A Study of the Global Supply of Lawyers", Indiana Fournal of Global Legal Studies, Vol. 20, pp. $1071-1137$.

Organization of American States Inter-American Commission on Human RiGHTS (2009). "Report on the Rights of Women in Chile: Equality in the Family, Labor and Political Spheres".

Power, Margaret (2004). “Gender and Chile's Split Culture: Continuing Contradiction in Women's Lives", Harvard Review of Latin America, en http://revista. drclas.harvard.edu/book/gender-and-chiles-split-culture.

Ramirez, Natacha (2016). "Estudio desvela a los colegios de élite en Chile: Dan formación "gerencial" y hacen competir a sus alumnos", en http://www.emol. com/noticias/Nacional/2016/10/20/827223/Estudio-desvela-a-los-colegios-de-elite-en-Chile-Dan-formacion-gerencial-y-promueven-la-competencia-entre-sus-alumnos.html.

Rodriguez, Kate (2007). "Golden, lazy days with a Chilean nana", en http://www. telegraph.co.uk/expat/4203818/Golden-lazy-days-with-a-Chilean-nana. html.

Segovia, Macarena (2017). "Estudiantes desafian al rector Sánchez en la UC: preparan consulta por objeción de conciencia", en http://www.elmostrador.cl/noticias/pais/2017/09/07/estudiantes-desafian-al-rector-sanchez-en-la-uc-preparan-consulta-por-objecion-de-conciencia/. 
Toro A. Evonne (2014). "Dónde se educan las familias más poderosas de Chile: Los Luksic y su devoción por The Grange School", en http://www.theclinic. cl/2014/07/31/donde-se-educan-las-familias-mas-poderosas-de-chile-losluksic-y-su-devocion-por-the-grange-school/.

Ugarte Cataldo, José Luis (2009). Tutela de derechos fundamentales del trabajador (Legal Publishing).

Ugarte Cataldo, José Luis (2011). "Las nanas de Zapallar", en http://www.elmostrador.cl/noticias/opinion/2011/03/04/las-nanas-de-zapallar/.

Walsh, Michael (2004). Opus Dei: An Investigation into the Powerful, Secretive Society within the Catholic Church in Chile (HarperCollins).

WATERS, Jaime (2015). "Snowball sampling: a cautionary tale involving a study of older drug users", International fournal of Social Research Methodology, Vol. 18, pp. 367-380.

Weissman, Iván (2016). "Hijitos de papá: investigación de Chicago boy revela que familias y colegios de origen siguen siendo determinantes para acceder a la elite", en http://www.elmostrador.cl/noticias/pais/2016/12/10/hijitos-de-papa-investigacion-de-chigago-boy-revela-que-familias-y-colegios-de-origen-siguen-siendo-determinantes-para-acceder-a-la-elite/.

Williams, Joan C. y Dempsey, Rachel (2014). What Works for Women at Work (NYU Press). 


\section{NORMAS GITADAS}

\section{Chile}

Constitución Política de la República 1980. D.S. 100 de 17 de septiembre de 2005, fija el texto refundido, coordinado y sistematizado de la Constitución Política de la República.

Código del Trabajo. DFL 1 de 16 enero de 2003, fija el texto refundido, coordinado y sistematizado del Código del Trabajo.

Ley $\mathrm{N}^{\circ}$ 20.609, Establece medidas contra la discriminación, D.O. 24 de julio de 2012.

\section{Estados Unidos}

42 U.S.C. Sec. 2000e (k) (2018). 


\section{JURISPRUDENGIA CITADA}

\section{Estados Unidos:}

Price Waterhouse v. Hopkins, Corte Suprema, 490 U.S. 228 (1989). 